\title{
Research on Problems in Economic Management of Modern Enterprises and Its Innovative Development Road Wenshan Zhao
}

\author{
Huanghe Science and Technology College, Zhengzhou, 450006, China
}

Keywords: Economic management of economic enterprises; problems; innovative development

\begin{abstract}
The modern economic management embodies the emphasis of enterprise extension. The enterprise should accept the novel concept and make the underlying mechanism followed by economic management run through the daily detailed regulation. The hidden difficulties and drawbacks should be identified at any time and corrected carefully. The economic management of modern enterprises is a complex process and will experience a long-term exchange stage. After continuous exploration, the new feasible path can be summarized and the new modern management framework can be built.

Modern enterprise management cannot leave the preset economic management. In the common operation, the high-level economic value should be highlighted. The preset management precondition is to define the fundamental duty and change the old management organization. The enterprise management path has the intrinsic operating path and hidden deep logic. It is required to follow the real state, accept the new management concept and promote the the modern management expansion. At the same time, the new mechanism followed by the economic management should be created and the optimal system should be built. The old perception cannot be neglected and should be updated at any time. For the built management framework, attention should be paid to the subsequent review and find the problems.
\end{abstract}

\section{Define the essence of management}

The economic management of modern enterprise is the corporate identity in modern times. The underlying connotation of economic management integrates the daily economic activities, original principles of management category, selected management idea and management path in the supporting architecture. From the system built, the modern economic management orderly links the enterprise economy and corresponding management process in the macroscopic architecture.

From the essential viewpoint, it is intersected with the economy with the category of management and subject. The economic management in modern times reflects the deeper-level operating concept, aim followed by management and central interest of enterprise, which constructs the stable guarantee followed by enterprise progress. The daily production, continuous operation control, quality of selling products and various links involved by finance should be arranged. In this case, the multiple sourced of enterprise can be gathered orderly. The economic management under the new situation extends the enterprise advantages and promotes the long-term enterprise extension.

From the modern perspective, the system built by economic management should pay attention to the connotation of following levels. First, create the organizational structure within the complete framework and define the subdivided branch responsibilities. In the common management, the relevant economic documents should be collected properly kept. The periodic mechanism should be developed and the management efficiency in the real state should be assessed. Second, strengthen the resource control in the internal architecture, pay attention to the raw material purchasing in the initial stage, continuous production and processing and corresponding service process. Next, strictly follow the pre-proposed related laws and regulations and reconcile the multiple contradictions properly. 


\section{Fundamental nature of economic management}

Under the new situation, the enterprise management in modern times embodies the multi-level changes. For the common management, the fundamental nature in the economic management architecture should be defined and the features should be deeply analyzed. In addition, the economic management in each period should be guided to have orderly and comprehensive development combined with the reals state obtained from survey. Specifically, the fundamental nature of economic management includes the following emphasis:

(I) Set the evaluation indicator

The common enterprise economic management is closely related to the decision of the management. The decisions of leaders will be set as the monthly financial indicators and corresponding annual indicator. The multi-level indicators reflect the original management guideline. The manager should adjust the marketing policy, common operation and production technology in each period so as to improve the strength of comprehensive architecture and get close to the preset objective.

(I) Closely associate the common work

In the usual management of modern enterprise, the subdivided branch items are associated with the amount deployment and real use. The common operation of enterprise is conducted around the long-term progression objective. The common management involves the staff in the enterprise and preset departments because the real efficiency embodied by the economic management is closely related to the individual income and overall enterprise earnings. The preset measures can be protected only by creating the optimal atmosphere to obtain the expected real efficiency.

(II) Embody the comprehensive tendency

The common work in the economic management framework has comprehensive features. The value of origin is taken as the foundation and the comprehensive government is conducted for the various subdivided branches. Driven by the price, the enterprise integrates the common production process and operation control. The multi-level material conditions are controlled and planned, thus improving the preset economic efficiency. This means that the comprehensive nature of economic management should cover multi-level comprehensive connotation in the new period.

\section{Drawbacks in management}

From the current situation, the common management path of enterprise lacks of completeness. The subdivided multiple link has hidden difficulties and leakages. The various connected links cover the internal inspection and check, human resource control and safety production within the category of details.

(I) Backward internal inspection

The proposed management process of enterprise fails to break the old circular thinking and follow the times. With the network extension and the progress of electronic science and technology, the enterprise should accept the network and perfect the management network under the (collaboration of network technology. However, many enterprises fail to update their perception, accept the traditional internal control and follow the (process of manual review, thus wasting the precious time, but failing to improve the effectiveness of inspection.

(II) Neglect of normal training

The (architecture of personnel deployment is improper and the normal training model is not built. With the change of situation, the old training subject and skills lack of fundamental value. The frequent change of employees hinders the preset working process. The enterprise pays less attention to the usual internal training and fails to transfer the accumulate precious experience. Under this state, the human resources in the internal framework are hard to integrate, thus leading to frequent dismissal of core employees.

(III) Weak safety awareness

The process followed by enterprise engineering acceptance and product production should have 
complete security control. The construction enterprise embodies this emphasis. The enterprise safety awareness is weak and the safety responsibilities are not clear. The production is highlighted and the safety is neglected. Some enterprises even lack of corresponding laws and regulations and attempt to escape the punishment in case of any accident. The increase of benefits in each time period is considered purely and the safety control is neglected, thus hindering the smooth operation.

(IV) Lacking of capital structure

The capital structure of enterprise is improper and the asset liquidity is weak. The proportion of liabilities in the category of assets is great, with high risks. The financing decision in each time period fails to reflect the clear operation direction, leading to the deviation. The financing decision is also a fault.

(V) Chaotic internal relationship

The preset financial decision of enterprise generally relies on the experience, thus bringing fault decision under normal situation. The internal control embodies the chaotic tendency. The financial risk is a common management drawback. The inherent internal architecture of enterprise and superior-subordinate management architecture are mixed. The interest deployment and amount use authority are not clear. The chaotic management shortens the amount use effectiveness and leads to loss. The safety of amount flow and corresponding integrity attribute are hard to maintain.

\section{Create the new path}

(I) Enhance the internal inspection

The enterprise should reasonably deploy the unique financial staff, enhance the audit inspection in the internal architecture and follow the subdivided working features and allocate the employees cautiously. The deployment scheme of human resources should mobilize the enthusiasm of employees. In addition, the enterprise should conduct supervision and inspection and improve the common working efficiency; emphasize the internal audit and conduct business in order. The internal related departments and upper-lower departments should be clear about their responsibilities and conduct regulation orderly. The amount use efficiency can be improved and the integrity of amount use can be guaranteed.

(II) Build the warning system

The analysis system for financial indicators cannot leave the long-term warning mechanism. The preset warning system of enterprise can be divided into two classes: long-term and short-term. The indicator system built integrates the common profitability, solvency of enterprise, economic performance in each period and hidden progress potential. These clear indicators can reflect the multi-layer profitability. The return rate related to total assets and profit probability related to cost and consumption reflect the profitability in the overall architecture.

(III) Adopt the technical support

With the technology development, the information communication speed is accelerated. The financial system of enterprise has higher requirements. The technical support in the supporting architecture includes the financial software support. This kind of new software can identify multiple information with risk. According to the economic information collected, the feasible decision can be made together with the manager. This can escape the economic threat in the future and embody the safety regulation. Whether the enterprise decision is accurate is closely related to the enterprise fate. The enterprise in the technical support architecture can obtain fair and objective information.

(IV) Forecast the cash flow

The short-term warning system cannot be neglected. For the establishment of short-term warning, a clear budget of cash flow in this period should be made. The financing object of enterprise is the dynamic trend of cash. Whether the enterprise is maintained is related to the short-term profit as well as whether there is sufficient expenditure. The original precondition of warning is the earning of enterprise. For enterprise under stable operation, the operating account, amount payable and inventory goods are stable. In this case, the usual operating activity and net cash will be beyond the net profit brought by operation.

The budget of cash flow structuring is an important link of economic control. The accurate 
budgeting can provide cognizable warning information for diversified enterprises. The operator can take feasible control measures according to this kind of information collected. Thus, the clear budget is made. The subdivided objective is preset, collected and summarized cautiously. The rolling cash budget is made.

(V) Optimize the review regulation

The overall system of economic management is the optimal model and method. The economic management system is confirmed and built by the leader selected by the enterprise. However, in the continuous execution, the supervision and inspection involved by execution relies on the subdivided responsible body to have real operation. For the enterprise in modern times, the usual review mode should be optimized, the review process of link subdivision should be adopted, the judgment result should be considered comprehensively and regarded as the basis for preset model. The competent leaders should pay attention to the regular inspection and organize personnel to participate in the usual review links.

The accurate results from multiple judgments can identify the working efficiency under the real situation. The hidden and long-term difficulties should be changed and perfected orderly. The economic consideration and review should be added with the advanced performance inspection indicator. The subdivided review items should be designated to the staff in the enterprise. In the continuous review, the clear responsible body should be confirmed. This can provide the optimal guarantee for the subsequent revolution.

\section{Discussion}

The enterprise leader should be clear about the urgency of economic situation and drive the staff to participate in the economic management; confirm the scientific management mechanism and adopt the optimal regulation to restrict the related members; following the intensive guidance and change the old management under the intensive situation.

With the network extension, the common operating regulation is divided into the overall information architecture. The information management path is characterized by effectiveness and convenience. The now model under the real-time circumstance is adopted to promote the economic operation and avoid the hidden risks under progress. This can shorten the hidden errors. By relying on the information path, the enterprise executives should communicate and dialogue with the grass-root staff to know the opinions of employees and be clear ab out the thinking dynamics of grass root. This can make the optimal humanistic mechanism.

The complex process of economic management involves the multi-layer data collected. To make progress, the enterprise should build the new database, create the analysis mode under the big data situation, build the basic resource-based new framework; analyze the numerical results obtained by statistics and highlight the data mining; follow the multiple resources in the database to judge the progress direction of products. This expands the product category, promotes the increase of marketing earnings and create a suitable service model.

\section{VI.Conclusion}

The economic management path of modern enterprises has various drawbacks. It is required to optimize the economic management, ensure the enterprise progress in the new times and create the higher-level safety management under the collaboration of technology; properly deploy the internal financial personnel and enhance the internal audit; build the effective warning system and make the clear budget regulation according to the cash flow in each period. In addition, the enterprise should crate multi-level analysis indicators and build the long-term supporting warning because the new path can be created only by building the management guarantee under the comprehensive situation. 


\section{References}

[1] Wang Liyun. On Problem in Economic Management of Modern Enterprises and Its Countermeasures[J]. Business Economy, 2013(12),22:54-55.

[2] Su Yanjun. Innovation Strategy of Enterprise Economic Management under New Situation[J]. Modern Economic Information, 2014(02),11:22.

[3] $\mathrm{Hu}$ Haixia. Problem in Economic Management of Modern Enterprises and Its Countermeasures[J]. Modern Economic Information, 2013(09),15:93.

[4] Guo Ye. Thinking on Innovation of Enterprise Economic Management under New Situation[J]. Operation Management, 2013(15),18:81.

[5] $\mathrm{Hu}$ Bo. Research on Problem in Economic Management of Modern Enterprise and Its Measures[J]. Modern Economic Information, 2013(04),19:159. 